\title{
The Results of Borehole Acoustic Imaging from a Granite in the Jihlava District, Czech Republic: Implications for Structural Geological Research
}

\author{
Lucie Nováková ${ }^{1}$, Petr Novák ${ }^{2}$, Milan Brož ${ }^{1}$ Karel Sosna ${ }^{3}$, Michal Pitrák ${ }^{4}$, Jana Kasíková ${ }^{2}$, Lenka Rukavičková ${ }^{5}$ \\ \& Lukáš Maňák ${ }^{5}$ \\ ${ }^{1}$ Institute of Rock Structure and Mechanics, Academy of Sciences of the Czech Republic, v.v.i., Prague, Czech \\ Republic \\ ${ }^{2}$ Isatech Ltd., Prague, Czech Republic \\ ${ }^{3}$ ARCADIS Geotechnika Inc., Prague, Czech Republic \\ ${ }^{4}$ Aquatest Inc., Prague, Czech Republic \\ ${ }^{5}$ Czech Geological Survey, Prague, Czech Republic \\ Correspondence: Lucie Nováková, Institute of Rock Structure and Mechanics, Academy of Sciences of the \\ Czech Republic, v.v.i., V Holešovičkách 41, 18209 Prague 8, Czech Republic. Tel: +420-266-009-349. E-mail: \\ lucie.novakova@irsm.cas.cz
}

Received: August 27, 2012 Accepted: September 20, 2012 Online Published: September 28, 2012

doi:10.5539/jgg.v4n4p92 URL: http://dx.doi.org/10.5539/jgg.v4n4p92

\begin{abstract}
The paper presents utilisation of the acoustic borehole imaging method within the frame of structural geology research. Acoustic borehole imaging is a useful tool describing borehole walls. The method allows an identification of various inhomogenieties along the borehole including fractures. Despite the more or less subjective nature of interpretation of the acoustic borehole imaging similar to other geophysical method interpretations, is a careful comparison of the interpreted fractures and the fractures observed on a core allows us to orient both core and fractures. Furthermore it is possible to determine direction of present kinematic indicators on the oriented core (and fracture planes). Identified fault planes and kinematic indicators are valuable information for structural geology research, particularly for paleostress analysis. The procedure described here was applied in the PDV-1 borehole drilled in the immediate vicinity of the quarry near the Panské Dubenky village, Jihlava district, Czech Republic, Europe. The results are consistent with previous standard structural geology research conducted in the quarry.
\end{abstract}

Keywords: acoustic borehole imaging, structural geology, paleostress analysis, granite

\section{Introduction}

Acoustic television imaging systems use an ultrasonic pulse-echo configuration with a $0.5-1.5-\mathrm{MHz}$ transducer. The transit time and amplitude of the reflected acoustic signal are recorded as photographic-like images, and the transit-time data can be used to generate high-resolution caliper logs (Williams \& Johnson, 2004). High resolution and often nearly complete borehole coverage images are interpreted at an interactive graphics workstation. When the image is "unrolled" and displayed from $0^{\circ}$ to $360^{\circ}$, linear features intersecting the borehole appear as sinusoids (Rider, 1996). Bedding, fracture features, faults, stratigraphic features, and many other features can often be manually or (semi-) automatically identified and quantified (Ye \& Rabiller, 1998). Gaillot et al. (2007) described induced fractures, folds, faults, small and horizontal fractures as tectonic features usually recognized on borehole images. In addition to identifying fractures and faults, borehole imaging tools are routinely used in support of detailed core analysis for a variety of other applications such as sequence stratigraphy, facies reconstruction, stratigraphy, and diagenetic analysis. Acoustic image logs reveal a similar natural fracture population, but generally image slightly fewer fractures and do not reveal rock fabric due to their lower resolution. However, due to their full coverage, acoustic images can reveal drilling-induced borehole wall tensile fractures, breakouts, and petal-centerline fractures (Gaillot et al., 2007). Drilling-induced fractures, breakouts, and petal-centerline fractures that are thought to form just ahead of the drill bit then provide 
additional constraints on the orientation of the minimum horizontal regional stress (Zoback et al., 1985). To the knowledge of the authors, acoustic borehole imaging has only previously been used twice in the Czech Republic. Maros et al. (2002) and Sebes \& Szongoth (2002) presented results from the granitic Potůčky-Podlesí Massif, whilst Buránszki et al. (2006) presented results from the granitic Melechov Massif.

A $100 \mathrm{~m}$ deep borehole was drilled within a quarry near the village of Panské Dubénky (Figure 1) during the project "Research of Intergranular Porosity Influence on Deep Geological Disposal into Geological Formations and Methodology and Measuring Apparatus Development" financially supported by the Ministry of Industry and Trade of the Czech Republic in years 2009-2013 (Nováková et al., 2010; 2011). The project has been conducted by research team consisting of Arcadis Geotechnica Inc., Isatech Ltd., Institute of Rock Structure and Mechanics of the Czech Academy of Science, Czech Geological Survey, Progeo Ltd. and Nuclear Research Institute Inc. The borehole acoustic imaging was measured and interpreted by Aquatest Inc. The borehole and the core have been studied extensively using a range of tests and variety of different methods in order to characterise the rock environment in both field and laboratory conditions (e.g. Sosna et al., 2009; Nováková et al., 2010; Vaněček et al., 2010). Those tests included a tectonic description of the core and acoustic borehole imaging. Independently derived details of brittle tectonic structures in the area surrounding Panské Dubenky have been described previously by Vaněček et al. (2005). The specific aim of this paper is to demonstrate the considerable advantages of undertaking the description of the core and acoustic borehole imaging at the same time as studying the tectonic history in the vicinity of the borehole.
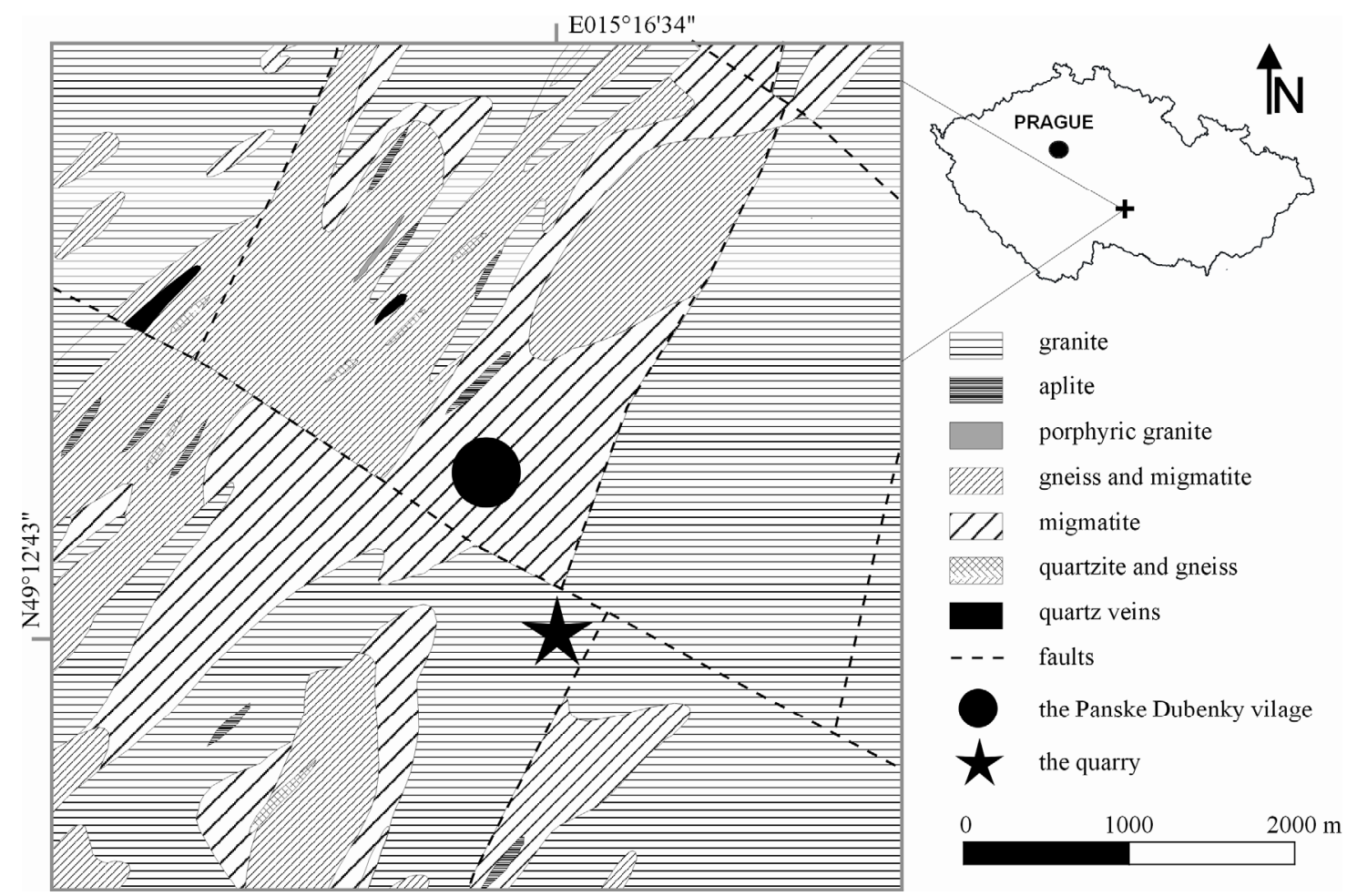

Figure 1. A schematic geological map of the studied locality with capital city of the Czech Republic - Prague (modified after Hron, 1995)

\section{Geological Setting}

The studied locality is situated near the village Panské Dubenky in the Jihlava District, Czech Republic, Europe (Figure 1). The locality is part of the Czech-Moravian Highlands. These highlands are the result of the comparatively recent uplift of older structural features including deep magmatic bodies dating from the Variscan Orogeny (Chlupáč et al., 2002). The structures were uplifted during the Alpine Orogeny, which ultimately led to the development of the present Carpathian Mountains. The uplift and accompanying arching occurred as a result of fracturing of the rock massif and movements along tectonic structures orientated NE-SW and NW-SE (Sosna et al., 2009). The most important unit in this region is the Moldanubian Zone, orientated NNE-SSW. The joint 
system of this zone is comparatively simple (Vaněček et al., 2005). In the post-tectonic period, the plutonic rocks solidified to form highly regular joint systems. The most important joint directions are $90^{\circ}$ to $120^{\circ}$ for Q-joints and $0^{\circ}$ to $30^{\circ}$ for S-joints whilst the diagonal joints are often orientated NE-SW and NW-SE (Dudek, 1962). The petrographic composition of the zone is quite monotonous as it is predominately Eisgarn-type two-mica granites with plagioclase and K-feldspar (Dudek, 1983).

The studied locality is characterised by medium-grained two-mica granite with varying volumes of feldspar phenocrysts (Figure 1; Hron, 1995). This granite is terminated to the west by a tectonic zone orientated NNE-SSW. In this zone, biotitic and silimanite-biotitic migmatites with cordierite mantle rocks are found. The contact between the granitic massif and mantle rocks was mapped approximately $800 \mathrm{~m}$ to the north of Panské Dubenky. To the south of the village is a tectonic zone orientated WNW-ESE. The western contact of the massif rocks have been tilted for about 500 metres (Rybaŕík, 1994). The studied granite quarry is situated within this tectonic block at an altitude of $693 \mathrm{~m}$. It is still active and covers an area of approximately $150 \mathrm{~m} \times 50 \mathrm{~m}$ with wall heights of between $10 \mathrm{~m}$ and $15 \mathrm{~m}$. Borehole PDV-1 was drilled in close vicinity of the from the quarry (about 50 meters).

\section{Methods}

The borehole acoustic imaging method employed in borehole PDV-1 uses reflected acoustic signals to create an oriented scan of borehole wall. The BHTV-ABI40 probe sensor (Advanced Logic Technology) rotates and frequently emits and receives ultrasound impulses. The travel time of the reflected signal is recorded down the borehole. The well-known speed of sound waves in water is then used to draw the shape of the borehole wall from the travel time. The amplitude of the acoustic signal received from the borehole wall is used to reveal plane inhomogeneities along the borehole wall. Thereafter, WellCAD software was used to process the data in order to provide an overall three-dimensional description of the borehole (Figure 2). The position, azimuth, and dip of the fractures were then interpreted. The plane of each fracture was determined through superimposing a sine wave shape over the amplitude or radius (travel time) of the unfolded oriented borehole wall image.

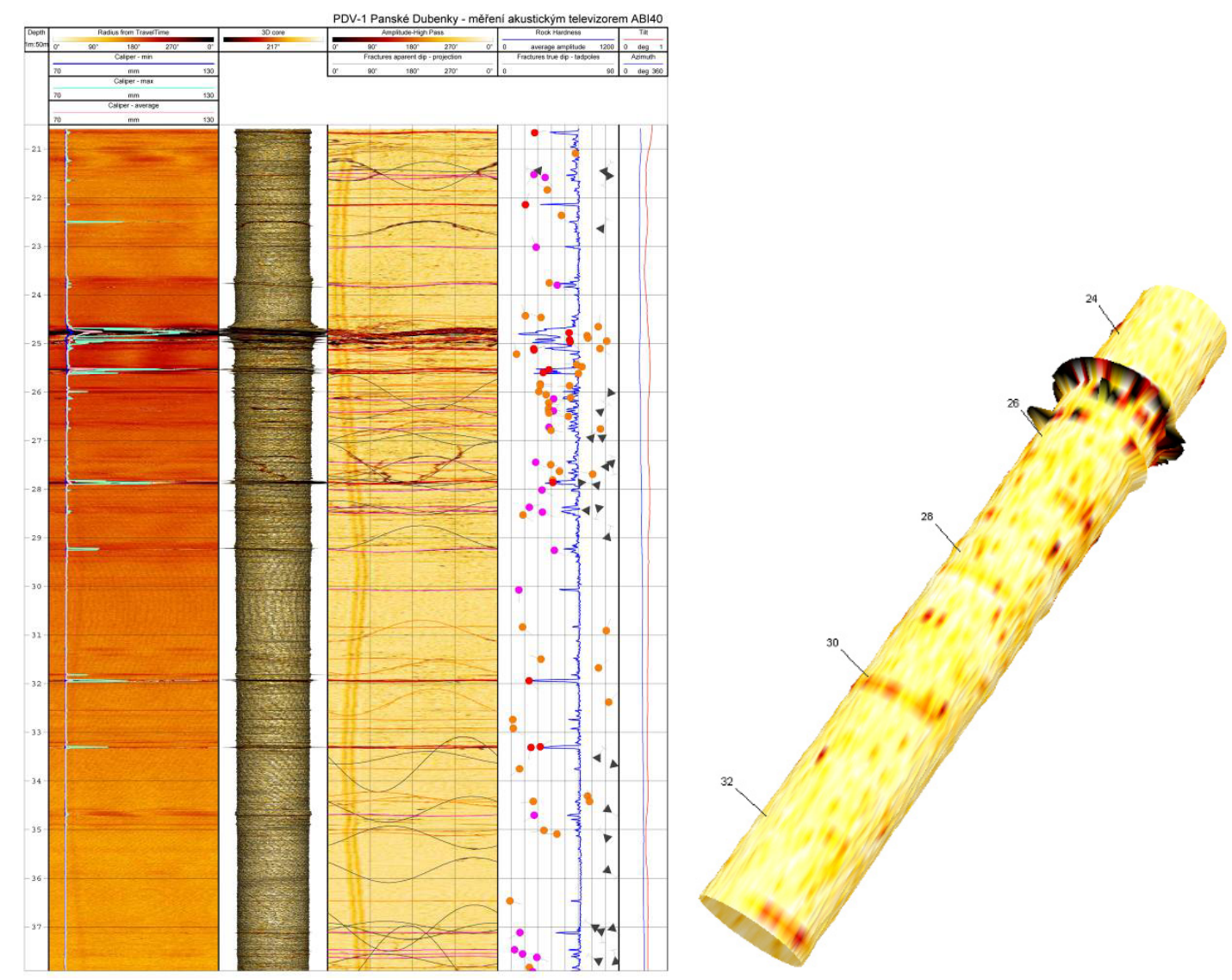

Figure 2. The interpreted results of the borehole acoustic imaging in borehole PDV-1. The unfolded image of the borehole wall and its interpretation is on the left. The three-dimensional model is on the right 
The fractures shown by the acoustic borehole imaging were classified in order to facilitate processing. It was proposed that there should be a direct relationship between the form of the ultrasound wave reflection and the geological significance of the respective fracture. The interpreted fractures were subjectively differentiated according to an ultrasound wave amplitude loss, into three categories of importance: high, medium, and low. An additional category was established for fractures with fragmentary exposure. A fracture was categorised as being of high importance when its reflected wave amplitude attained at least $60 \%$ of the maximum reflected wave amplitude of the fracture PDV-1. If the amplitude was found to be lower than $30 \%$ a fracture was categorised as being of low importance while if the amplitude was found to be between $30 \%$ and $60 \%$ a fracture was categorised as being of medium importance. Fractures with complete exposure in the unfolded borehole wall image were regarded as natural while those with incomplete exposure were regarded as induced; these refer to fractures that occur naturally within the granite and those that formed during drilling, respectively. It is, however, important to note that the fracture separation was based solely on the observed acoustic wave and eventually might not precisely reflect their geological properties.

The PDV-1 core was studied carefully. The observed joints were correlated to joints indicated by the borehole acoustic imaging. Thereafter, the core was examined for fractures with kinematic indicators (Figure 3). Those fractures that contain fragments of the core were oriented using the characteristic fracture sets. The orientations of the kinematic indicators (striations) were measured on the oriented fragments. Finally, a paleostress analysis was conducted using the Gauss method (Žalohar et al., 2007; Žalohar, 2009).

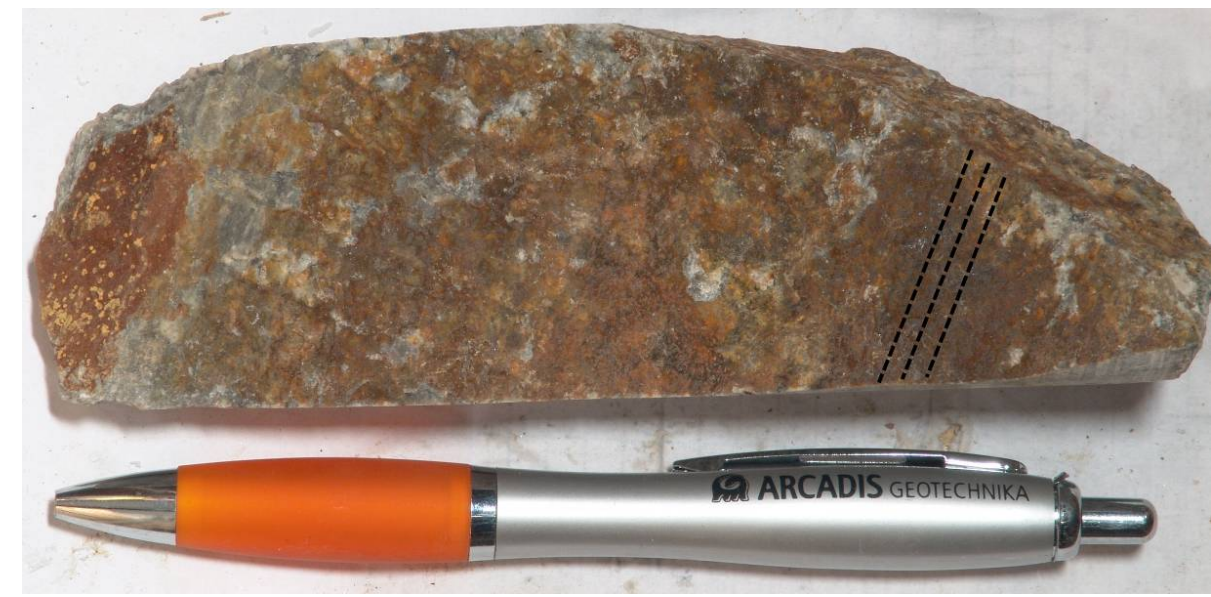

Figure 3. The observed striations on a fault plane as seen on a core fragment from borehole PDV-1

\section{Results}

The borehole acoustic imaging listed a total of 357 joints within borehole PDV-1. The method differentiated induced and natural joints, and their relative degree of importance according to an ultrasound wave amplitude loss. The complete contour diagram of poles to joints clearly shows three orthogonal joint systems, which is quite typical for granites (Figure 4).

Four types of fractures were identified in the borehole through borehole acoustic imaging method (induced, low significance, medium significance, and high significance). Figure 5 shows the rock type within the borehole, the degree of fracturing, and the distribution of the fractures in relation to its type. Figure 6 presents the vertical distribution of the different types of fractures. It clearly shows that the induced joints are predominately sub-vertical. There are slight changes in the prevailing joint orientation according to depth down the borehole. The joints are significantly more frequent between $40-50 \mathrm{~m}$ and $60-70 \mathrm{~m}$, whilst only a few joints were observed between $80-100 \mathrm{~m}$. According to the borehole acoustic imaging, the natural joints of high significance dip gently or are sub-horizontal. Of these joints, all but one occurs between $20-50 \mathrm{~m}$. The natural joints of medium significance are usually sub-horizontal although sub-vertical joints are also present, especially in the lower half of the borehole. The number of these joints decreases with increasing depth. The natural joints of low significance are the most common and display variable characteristics. While sub-horizontal joints are dominant between 30-60 m, all three joint systems are present above and below. Again, the number of the joints decreases with increasing depth. A detailed comparison between the joints interpreted from the borehole acoustic imaging 
and the joints visible in the core provided a relatively high degree of correlation. However, it was noted that the borehole acoustic imaging results and core observations may be affected by shifts of up to $50 \mathrm{~cm}$. Despite the borehole acoustic imaging based classification of some fractures was found different comparing to the core observation, in general the classification was found adequate.

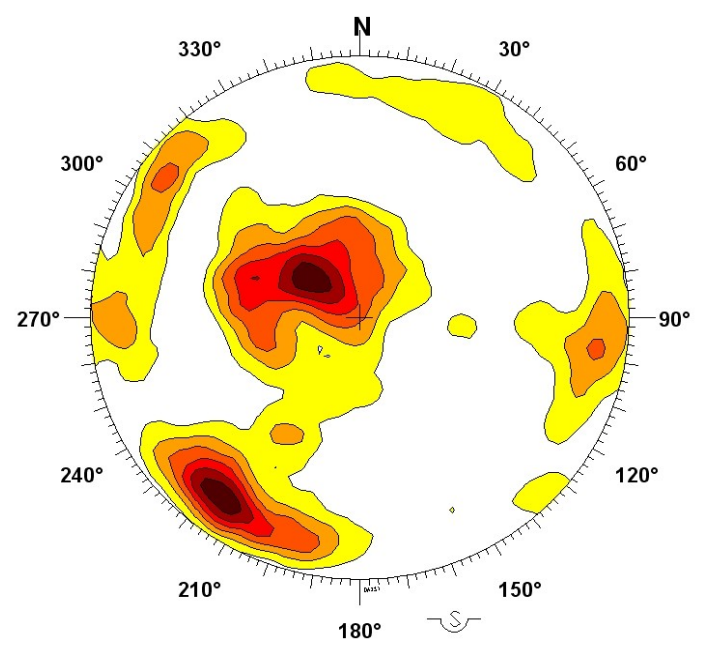

Figure 4. A contour diagram of poles to joints within borehole PDV-1, determined through borehole acoustic imaging. Contour interval $1 \%, n=357$

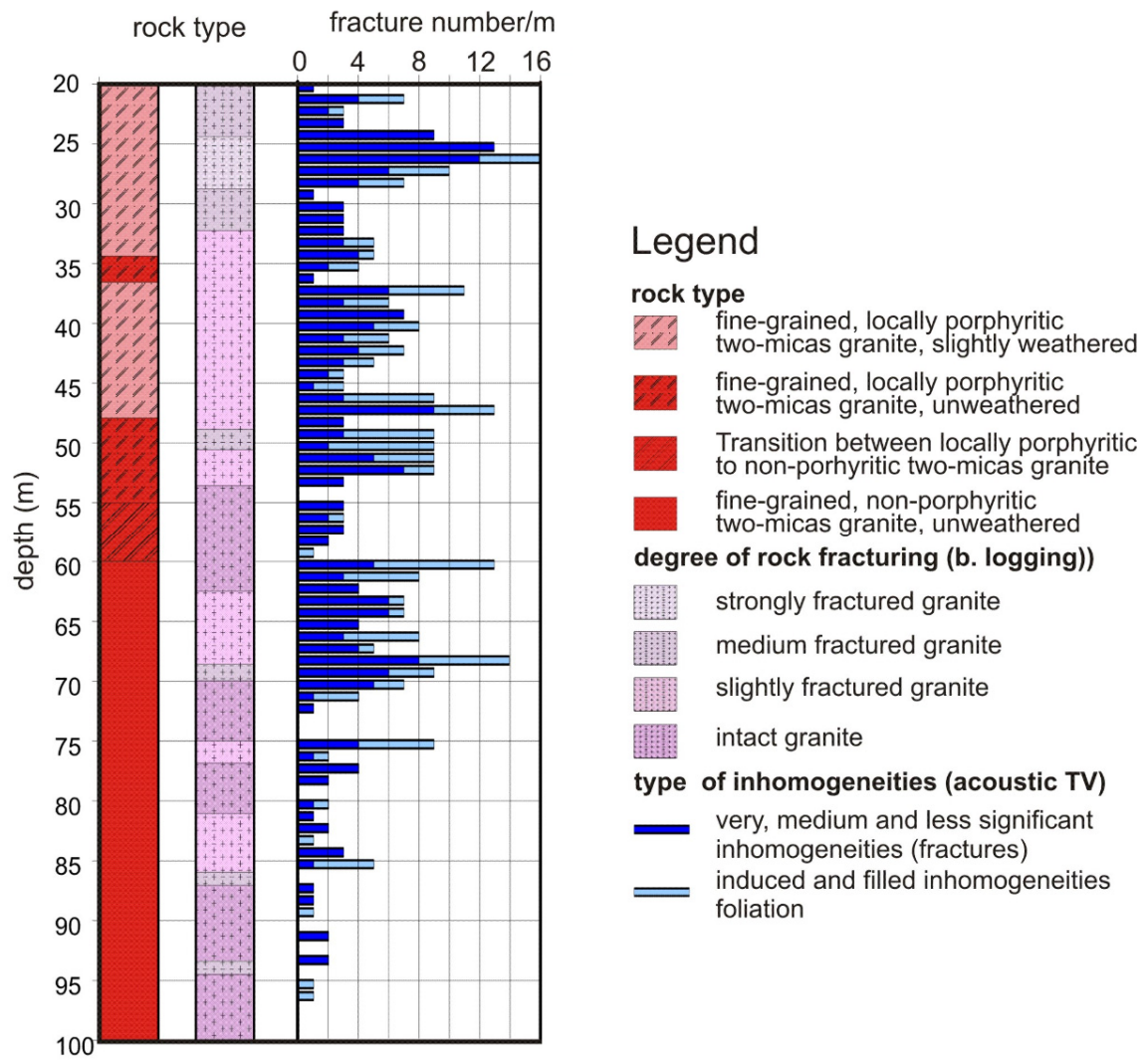

Figure 5. A geological profile of the borehole and the distribution of the fractures 


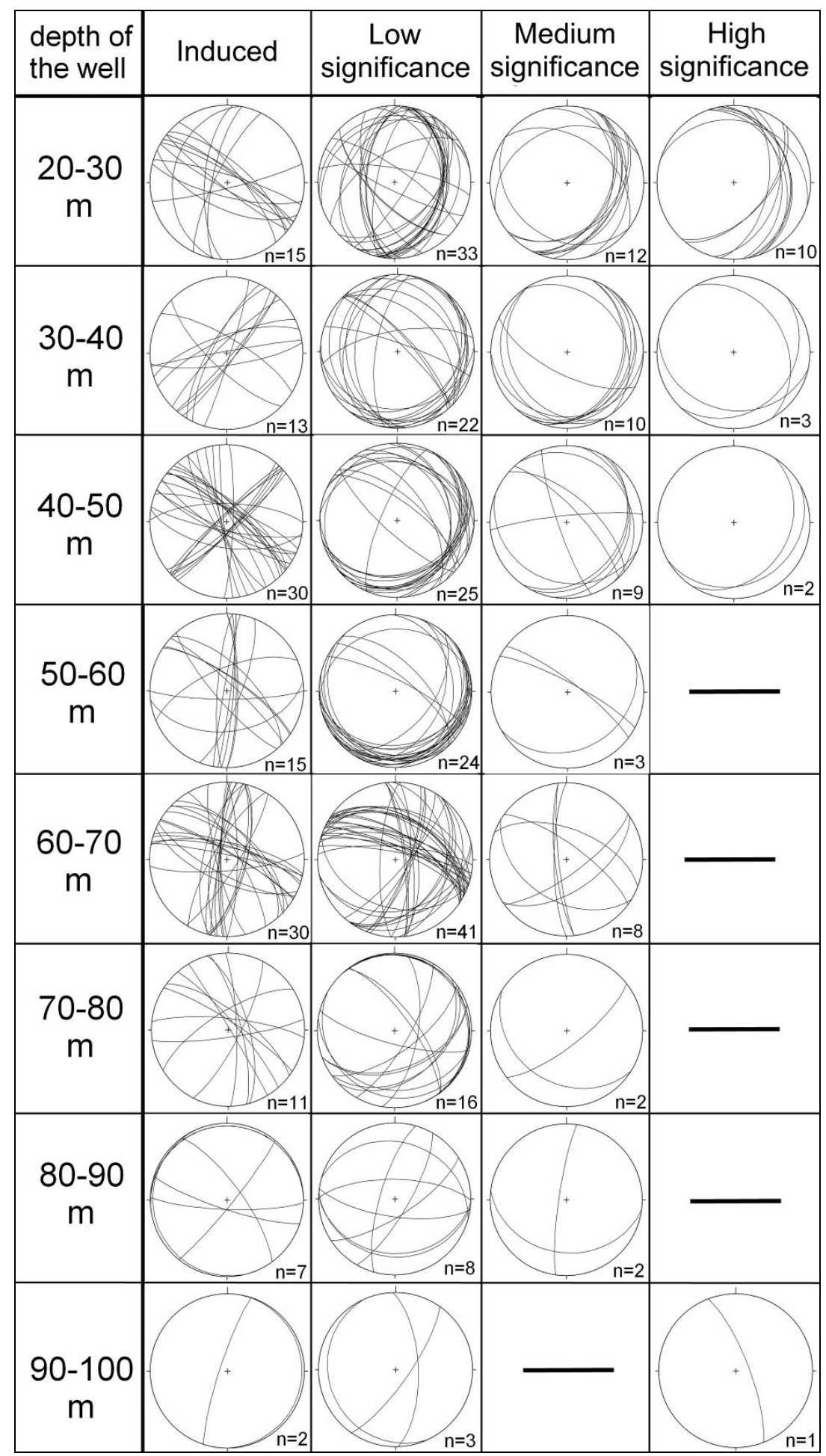

Figure 6. Stereograms grouped according to depth down the borehole (vertical) and the type of the joint (horizontal)

Within the core, eleven fractures were recognised as having kinematic indicators (usually striations) (Figure 7). Where two striations crossed each other on the very same fracture plane, two different movements along the plane were indicated. The Gauss paleostress analysis identified two tectonic phases (Figure 8). The two crossing striations pointed to the succession of these phases. The first phase was characterised by WSW-ENE compression whilst the second phase was characterised by NW-SE compression. While $\sigma 1$ was, in fact, horizontal, $\sigma 3$ was vertical during both phases. 


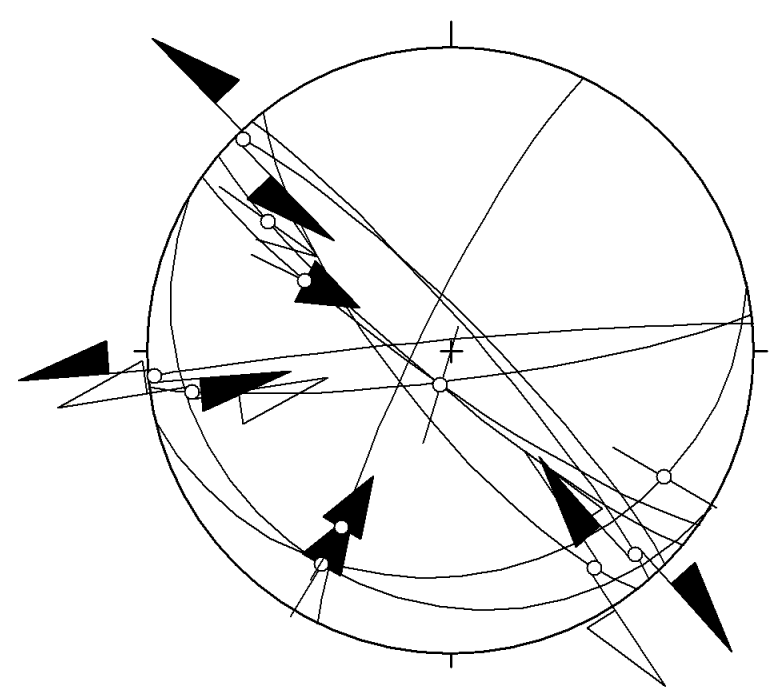

Figure 7. Stereogram of the faults found on the core with arrows determining the sense of movements $(\mathrm{n}=11)$
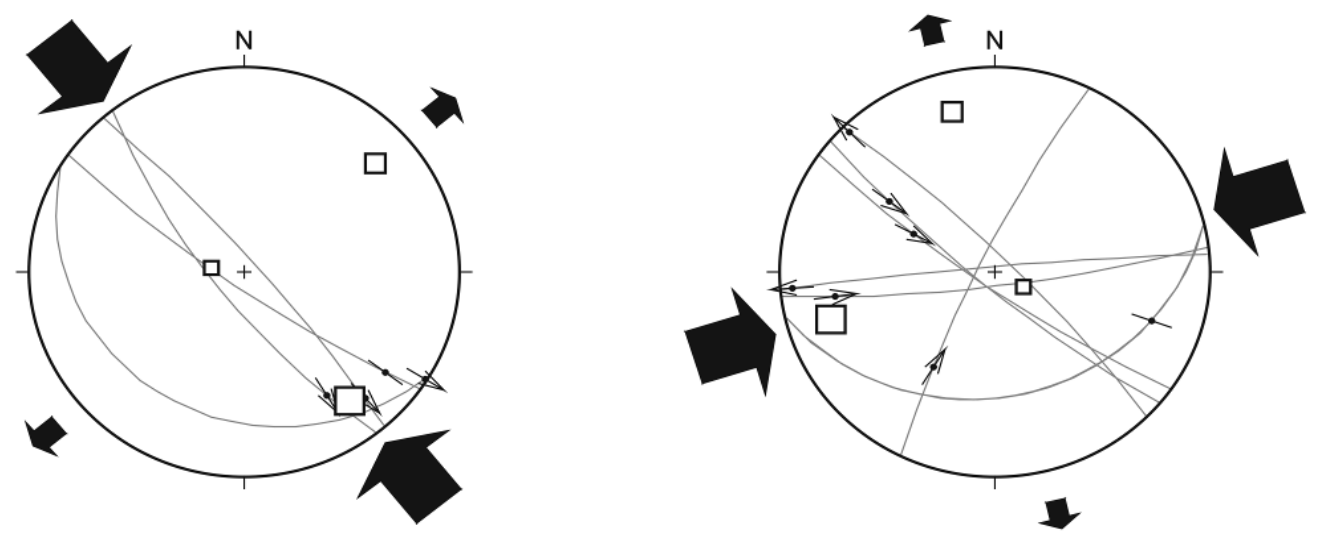

Figure 8. The results of the Gauss paleostress analysis on the faults found within the core. Left: younger phase $(n=4)$. Right: older phase $(n=7)$. The largest square represents $\sigma 1$, medium square $\sigma 2$, the smallest square $\sigma 3$.

The arrows show the compressional and extensional directions

\section{Discussion}

First, the reliability of the interpreted locations and orientation of the fractures had to be evaluated. The unfolded image of the wall of the borehole, and the list of fractures were compared to the core itself and the geological description of the core (Novák et al., 2010). These comparisons highlighted several important findings. It is clear that the interpreted fractures are generally similar to the actual ones although the acoustic borehole imaging method usually presented a detailed image that had shifted slightly with respect to the actual core. This is, of course, unsurprising given the positional uncertainty during drilling and with regard to the stored core. The distribution of the fractures described by the acoustic borehole imaging method and those visible in the core are likewise not identical. It was found that it was useful to categorise the fractures determined through the acoustic borehole imaging method into four categories (induced, high significance, medium significance, and low significance). However, such categorisations based strictly on the physical manifestation of the fractures have obvious limitations. For example, four of the fractures categorised as induced by the acoustic borehole imaging were found to in fact be faults. Similarly, the acoustic borehole imaging based categorisation of several other fractures did not correspond to that expected in the core. To define a practicable and reliable categorisation, it is essential to carefully and precisely decide upon the requisite criteria. One possible approach to defining these criteria is to first inspect the core and then categorise the observed inhomogeneities. Thereafter, a correlation could be made between the appearance of inhomogeneities in the amplitude image of borehole wall and the joint categorisation derived from the inspection of the core. If such correlations can be made, then inhomogeneities in 
the amplitude image of the borehole wall can be interpreted more reliably.

Information provided by acoustic borehole imaging is undoubtedly very useful. Previous research in the quarry described the structural geology of the area (Vaněček at al., 2005). Their pole to plane diagram shows four principal fracture planes (Figure 9). When both pole to plane diagrams were compared (cf. Figure 5 and Figure 9), it is evident that there is agreement between the two. This agreement demonstrates that both methods of structural geology data acquisition are able to generate reliable, comparable results.

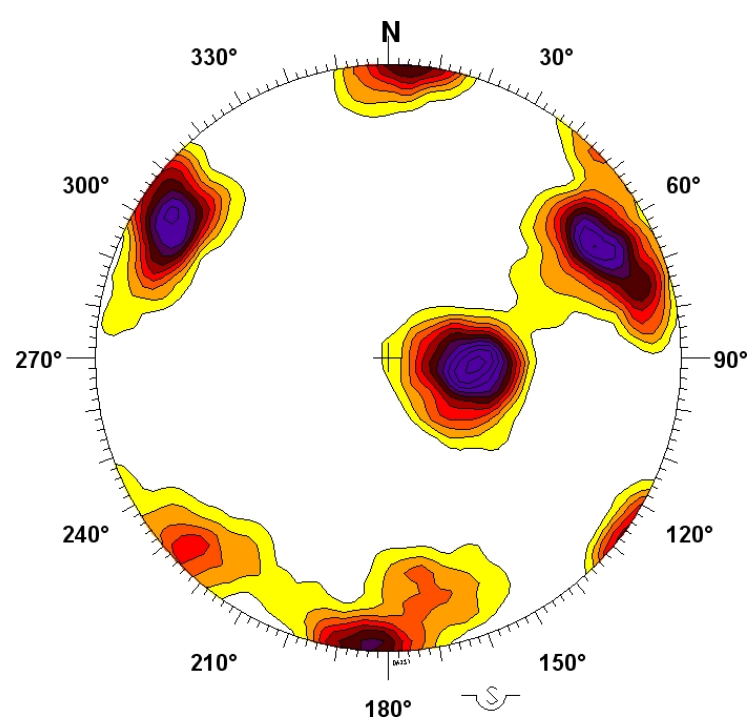

Figure 9. A contour diagram of poles to joints in the quarry, determined through measurements of structural geology (after Vaněček et al., 2005). Contour interval 1\%, n=153

The acoustic borehole imaging results alone cannot provide a complete illustration of the tectonics unless the joints and faults are differentiated and paleostress analysis is taken into account. Unfortunately, acoustic borehole imaging is neither able to differentiate between joints and faults, nor able to specify the sense of a movement along the planes. Therefore, an additional source of information is needed, and this has been attained in borehole PDV-1. The core was carefully examined for the presence of kinematic indicators. Finally, eleven faults were identified due to striations on the fault planes (Figure 3 and Figure 7). Using structural geological measurements, Vaněček at al. (2005) found a total of nineteen faults in the quarry at Panské Dubenky. Of these, the sense of movement could only be determined on five fault planes. Nonetheless, no significant differences exist between the core inspection and acoustic borehole imaging results and the structural data derived from the measurements within the quarry (cf. Figure 7 and Figure 10).
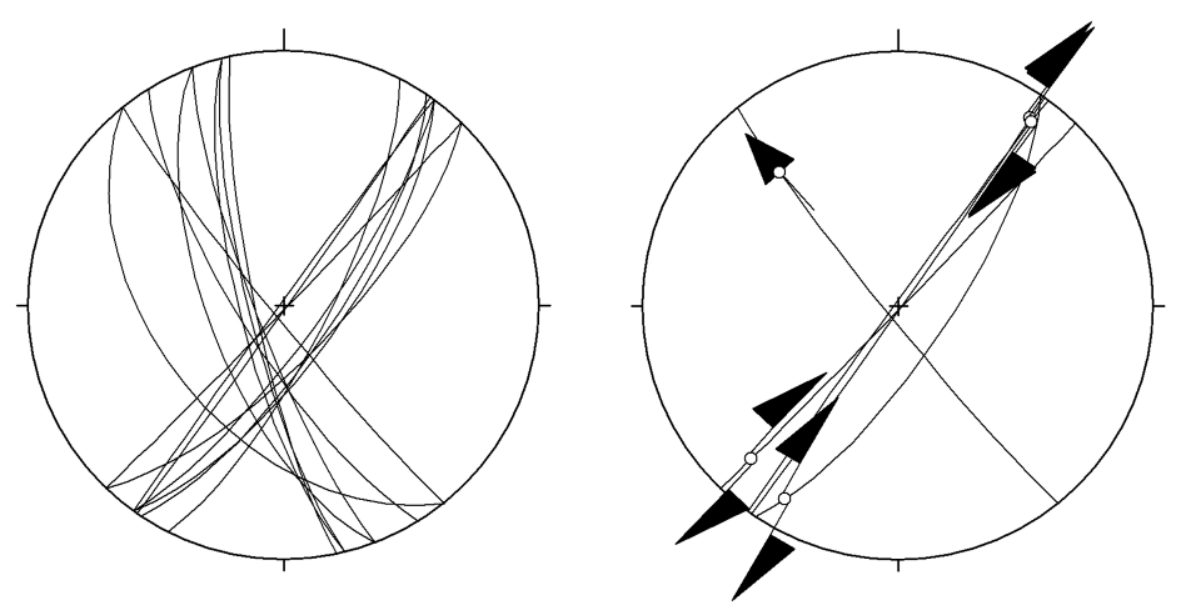

Figure 10. Stereograms of the faults measured within the quarry. Left: all faults $(\mathrm{n}=19)$. Right: faults with a determined sense of movements ( $\mathrm{n}=5)$ (after Vaněček at al., 2005) 
In fact, the sets are quite complementary. It was not possible to perform a paleostress analysis on the structural data derived from the measurements within the quarry due to the insufficient amount of data. The paleostress analysis was therefore performed on the faults defined through acoustic borehole imaging. The analysis was also undertaken on all the defined faults. The paleostress analysis performed on the faults defined through acoustic borehole imaging points to two different stress regimes. The same result was obtained when all the defined faults were analysed (cf. Figure 8 and Figure 11). From these results, it is clear that the acoustic borehole imaging method is a useful tool within the framework of research into structural geology.
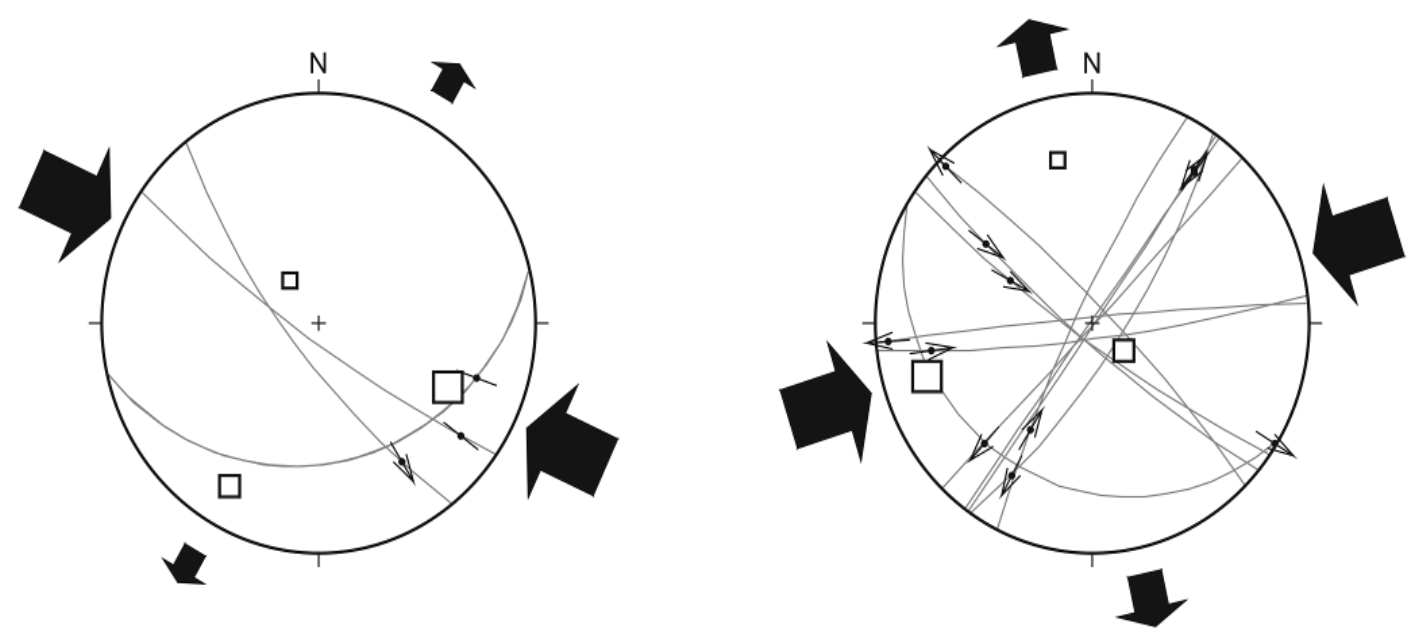

Figure 11. Results of the paleostress analysis on the all faults determined by examining the core and measured in the quarry. Left: younger phase ( $\mathrm{n}=3)$. Right: older phase $(\mathrm{n}=11)$. The largest square represents $\sigma 1$, medium square $\sigma 2$, the smallest square $\sigma 3$. The arrows show the compressional and extensional directions

\section{Conclusion}

The acoustic borehole imaging method is an undoubtedly significant source of structural geological data whilst further information may be attained from the borehole core when it is accessible and relatively intact. This study has shown that the results of acoustic borehole imaging together with a detailed core inspection are consistent with those derived from a classic structural geological survey. The acoustic borehole imaging probes are sophisticated tools and, consequently, the acquisition of these probes is understandably high. Considering these probes, the method is unlikely to become standard within structural geological research. However, the acoustic borehole imaging method is a powerful tool that may be applied in places where the terrain has already been studied from a structural geological perspective or where further data are required for reliable and highly detailed descriptions.

\section{Acknowledgements}

This work has been funded by the Ministry of Industry and Trade of the Czech Republic (FR-TI1/367) and by the Institute of Rock Structure and Mechanics AS CR, v.v.i. (A VOZ30460519). We are grateful to our friends, colleagues, and partners Progeo Ltd. and NRI Inc. for participating in the project "Research of Intergranular Porosity Influence on Deep Geological Disposal into Geological Formations and Methodology and Measuring Apparatus Development" (http://www.granite-porosity.cz). Authors thank to Dr. M.D. Rowberry for his careful proof reading and suggested language improvements, Prof. F. Salvini and Dr. J. Žalohar for free use of the DAISY3 (Salvini et al., 1999) and T-tecto 3.0 (Žalohar, 2009) software and anonymous reviewer for useful comments and suggestions.

\section{References}

Buránszki, J., Prohászka, A., \& Tóth, I. (2006). Report on geophysical logs in the Mel-5 borehole (Lipnice nad Sázavou, Czech Republic). Geo-Log Ltd. Budapest.

Chlupáč, I., Brzobohatý, R., Kovanda, J., \& Stráník, Z. (2002). Geological history of the Czech Republic. (in Czech). Academia. 436. http://www.academia.cz

Dudek, A. (1962). Legend of the geological map of ČSSR 1:200 000 M-33-XXVIII (in Czech). Geofond, Praha, 99. 
Dudek, A. (1983). In Mísař, Z. (ed.). Geology of the ČSSR I. Bohemian Massif (in Czech). SPN Praha, 333.

Gaillot, P., Brewer, T., Pezard, P., \& Yeh, E. (2007). Borehole Imaging Tools - Principles and Applications. Scientific Drilling, 5, 1-4.

Hron, J. (1995). Geological map of the Czech Republic, 23-32 Kamenice nad Lipou, scale 1:50 000 (in Czech). Český geologický ústav, Praha.

Maros, G., Palotás, K., Koroknai, B., \& Sallay, E. (2002). Tectonic evaluation of borehole PTP-3 in the Krušné hory Mts. with ImaGeo mobile corescanner. Bulletin of the Czech Geological Survey, 77(2), 105-112. http://www.geology.cz/bulletin/contents/art2002.02.105

Novák, P., Trpkošová, D., Plšková, M., Kasíková, J., Michálková, J., Najser, J., .., Záruba, J. (2010). Consecution and management of field works including final report of field works held by Arcadis Geotechnika and Isatech during 2010 (in Czech). Final report of the project FR-TI1/367.

Nováková, L., Brož, M., \& Novák, P. (2010). Comparative study of geophysical parameters and geochemical analysis in undisturbed granites. In Williams et al. (Eds.) Geologically Active. 2010 Taylor \& Francis Group, London, 2281-2288.

Rider, M. H. (1996). The Geological Interpretation of Well Logs (2nd ed.). Cambridge, England: Rider-French Consulting, Ltd.

Rybařík, V. (1994). Chivalrous and constructive stones of the Czech Republic (in Czech). Nadace střední průmyslové školy kamenické a sochařské v Hořicích v Podkrkonoší.

Sebes, L. Z., \& Szongoth, G. (2002). Investigation of granite inhomogeneity with borehole logging methods. $\begin{array}{lllll}\text { Bulletin of the Czech Geological Survey, } & \text { 77(2), }\end{array}$ http://www.geology.cz/bulletin/contents/art2002.02.127

Sosna, K., Brož, M., Vaněček, M., \& Polák, M. (2009). Exploration of a granite rock fracture system using a TV camera. Acta Geodynamica et Geomaterialia, 6(4), 453-463. http://www.irsm.cas.cz/?Lang=CZE\&Menu=25,29,0,0;\&File=Obsah/AGG/Contents/AGGC6_4\%28156\%2 909.htm

Vaněček, M., Trpkošová, D., Polák, M., Sosna, K., Michálková, J., Novák, P., ... Navrátil, T. (2010). Matrix permeability of granite rocks and validation of modelling solution. In Williams et al. (eds.) Geologically Active. 2010 Taylor \& Francis Group, London, 3765-3772.

Vaněček, M., Vaněček, M. jun., Verner, K., \& Žák, J. (2005). Characteristics of the geological situation of the research site in situ in granite quarry in Panské Dubénky (in Czech). Project TP-DP1: Methods and tools for the evaluation of the effect of engineered barriers on distant interactions in the environment of a deep repository facility - period 2005.

Williams, J. H., \& Johnson, C. D. (2004). Acoustic and optical borehole-wall imaging for fractured-rock aquifer studies. Journal of Applied Geophysics, 55, 151-159. http://dx.doi.org/10.1016/j.jappgeo.2003.06.009

Ye, S. J., \& Rabiller, P. (1998). Automated fracture detection on high resolution resistivity borehole imagery, SPE-49300, in 1998 SPE annual technical conference and exhibition proceedings, v.pi, Production operations and engineering/general. Society of Petroleum Engineers, 777-784.

Žalohar, J. (2009). T-TECTO 3.0 Professional Integrated Software for Structural Analysis of Fault-Slip Data, Introductory Tutorial 56. http://www2.arnes.si/ jzaloh/download_t-tecto.htm

Žalohar, J., \& Vrabec, M. (2007). Paleostress analysis of heterogeneous fault-slip data: The Gauss method. Journal of Structural Geology, 29, 1798-1810. http://dx.doi.org/10.1016/j.jsg.2007.06.009

Zoback, M. D., Moos, D., Mastin, L., \& Anderson, R. N. (1985). Well bore breakouts and in situ stress. Journal of Geophysical Research, 90(B7), 5523-5530. http://dx.doi.org/10.1029/JB090iB07p05523 